\title{
A Comparative Study of the Effects of Two Approaches of Dynamic Assessment on the Reading Comprehension of Iranian EFL Learners
}

\author{
Jila Naeini \\ English Department, Roudehen Branch, Islamic Azad university, Roudehen, Iran \\ E-mail: naeini.j@gmail.com
}

Received: $31-07-2014$

doi:10.7575/aiac.ijalel.v.4n.2p.54
Accepted: 23-09-2014

Published: 01-03-2015

URL: http://dx.doi.org/10.7575/aiac.ijalel.v.4n.2p.54

\begin{abstract}
The aim of this study was to examine and compare the impact of two Dynamic Assessment (DA) approaches, that is, Feuerstein's Mediated Learning Experience (MLE) and Brown's Graduated Prompt (GP) on Iranian EFL learners' reading comprehension. Therefore, a mixed methods approach consisting of a semi-structured interview, a pretest, an intervention program, a posttest, and a transfer test was applied to assess and compare the efficacy of two DA approaches. One hundred and two EFL learners taking a General English course at Islamic Azad University were assigned to two experimental groups (MLEG and GPG) and one comparison group (CG). The participants in the MLEG took part in the MLE, and the participants in the GPG participated in the GP intervention program. The results of the qualitative as well as the aggregate and disaggregated quantitative data analyses indicated that both intervention approaches of DA were effective in enhancing the learners' reading comprehension.
\end{abstract}

Key Words: Dynamic Assessment, Mediation, Mediated Learning Experience, Graduated Prompts.

\section{Introduction}

DA originally came almost about half a century ago as a reaction to dissatisfaction with traditional methods of assessment. As Cioffi and Carney (1983) argue, standard assessment procedures are not sufficient for estimating students' learning potential. They pin point that these assessment tools will not help instructors to identify the conditions under which students can be assisted to make progress. In fact, measuring students' current performance level cannot indeed provide assessors with enough information about learners' potential ability. Brown and French (1979) believe that learning potential is identified and assessed through applying the zone of proximal development (ZPD). In Vygotsky's ZPD theory, by offering appropriate forms of mediation, development of learners' mental functions can be intervened and guided grounding in DA.

Generally, DA has been implemented primarily in two approaches of interventionist and interactionist (Lantolf \& Poehner, 2004). Furthermore, there are different classifications of DA available in literature. Jitendra and Kameenui (1993) have identified five distinct models of DA which differ in their theoretical orientations, purpose of the assessment, the types of skills assessed, types of the tasks employed, nature of the interaction between the examiner and learner, and the quantity and the quality of the practical support accompanied with each DA model. The impetus for this study stemed from increasing attention researchers in the field of second language learning and teaching have been giving to Vygotsky's meditational approaches as well as comparing the effects of two general DA approaches: Feuerstein's Mediated Learning Experience (MLE) and Brown's Graduated Prompt (GP). MLE, according to Feuerstein, Feuerstein, Falik and Rand (2006), refers to the way in which the existed stimuli in the environment are changed in the form by an intervening agent, usually a parent, teacher, or others in the environment of the learner. They believe that this intervening agent, led by intention, culture, and emotional investment, chooses, increases, focuses, and otherwise arranges all the stimuli for the learner, based on a clear purpose for that learner's increased and effective actions.

In GP, Brown and her colleagues (Campione, Brown, Ferrara \& Bryant, 1984) administer the tests providing mediation that is aimed at training testees to solve problems through using certain principles. Brown's approach to DA is unique in that once testees have learned the pertinent principles and can solve problems with no help, the tester then tries to discover their ability to transfer what they have learned while solving novel problems (Poehner, 2005).

Actually, the significant impetus for the current study was exploring the efficacy of two intervention models of DA in diagnosing and enhancing the reading comprehension of Iranian EFL students. Therefore, the following research questions were attempted to be investigated:

1. Is there any significant difference between the effects of the mediations in Graduated Prompts and Mediated Learning Experience on the participants' reading comprehension?

2. Are the participants in the Graduated Prompt Group able to transfer the acquired knowledge to novel assessment contexts as realized in their transfer test scores? 
3. Are the participants in the Mediated Learning Experience Group able to transfer the acquired knowledge to novel assessment contexts as realized on their transfer test scores?

\section{The Study}

\subsection{Participants}

The students participating in all stages of this study were the undergraduates majoring in diverse fields at Islamic Azad University taking a GE course at the time of the research. To fulfill the objectives of the study, 102 EFL students drawn from an initial pool of 135 in six intact classes participated. Thirty three of the students did not take part in all stages of the project; therefore, they were excluded from the list of the participants. The result of a one-way ANOVA $(\mathrm{F}(2,99)=$ $0.24, \mathrm{P}=0.78>0.05, \eta 2=0.004)$ indicated that the participants did not show any statistically significant difference in their performance on the reading section of the Key English Test (KET, University of Cambridge ESOL Examinations, 2005) conducted to examine the participants' general reading comprehension at the outset of the study.

The participants were then randomly assigned to two experimental groups and a comparison group (CG). Regarding the types of the mediations the participants in the experimental groups received during the intervention programs, they were, henceforth, referred to as the GPG and the MLEG. It should be noted that the inclusion of the CG in this study was merely for providing the researcher with a base line for the comparison of the results. Therefore, the participants of the CG only took part in the reading comprehension tests.

\subsection{Instrumentation}

The Data collection instruments included: (1) a cognitive and metacognitive strategy questionnaire (CMSQ), and (2), a semi-structured interview as well as four assessment instruments of: (1) a Reading KET, (2) a reading comprehension pretest, (3) a reading comprehension posttest, and (4) a reading comprehension transfer test. Furthermore, two intervention programs were designed and carried out with the experimental groups. The intervention programs included: (1) the GP intervention program drawing on Brown's GP approach, and (2) the MLE intervention program drawing on Feuerstein's MLE. The instruments used for each intervention program included the Graduated Prompt Moves Protocol (GPMP) and the Mediated Learning Experience Taxonomy (MLET) for the GP intervention program and the MLE intervention program, respectively.

2.2.1 CMSA: In order to investigate the learners' cognitive and metacognitive strategy awareness (CMSA), Phakiti's (2003) cognitive and metacognitive strategy awareness was employed to explore how individual learners control their reading comprehension. It was also used in preparing the meditational instruments. The original questionnaire was modified and tested in a pilot study and then it was translated into Persian. The Cognitive and metacognitive strategies in Phakiti's CMSQ are composed of four subscales with a five Likert-scale questionnaire (Appendix 3).

2.2.2 Semi-structured interview: In order to explore the participants' perceptions, according to Berg (2001), interviewing is an efficient way of collecting information. In this study, semi-structured interviews were conducted to explore EFL learners' understanding of reading comprehension process and their difficulties in text comprehension. The data collected through interviewing along with the CMSQ data provided valuable information for devising the meditational taxonomies.

2.2.3 The Reading KET: In order to assess the homogeneity of the main study participants in terms of their general English reading comprehension, the reading section of the Key English Test (KET) which was developed and standardized by University of Cambridge ESOL Examination (UCLES), was used. Since only the learners' reading comprehension was under the investigation, only the reading section of the KET was applied. Therefore, this extracted reading section of the KET was, henceforth, referred to as the Reading KET which was taken from Khalifa and Weir (2009, pp. 233-243).

2.2.4 Reading comprehension tests: Three reading comprehension tests were developed by the researcher, tested and applied. Each test consisted of four passages and each passage was followed by six reading comprehension questions. The reading comprehension questions were focused on three reading comprehension domains: (1) Finding the main idea, (2) Guessing the meaning of the new words, and (3) inferencing; therefore, the reading comprehension questions are, henceforth, referred to as Main idea Questions (MQs), Guessing Questions (GQs), and Inferencing Questions (IQs), respectively.

According to Poehner (2005), the learner's true progress resulting from working on the learners' ZPD, should manifest itself in the tasks other than the main test. In fact, in DA approaches transfer tasks are included in order to determine "how far the learners can extend their knowledge and abilities beyond the assessment context, and how much assistance they require to do so" (p. 60). Consequently, the transfer reading comprehension test was developed to examine how far the learners in the GPG and the MLEG could extend their knowledge and abilities beyond the assessment context. Drawn on Feuerstein and Brown, who increased the difficulty and the complexity in creation of transfer tasks (Feuerstein, 2000), a higher readability index was considered for the passages of the transfer test.

2.2.5 Mediational instruments: The meditational instruments for the experimental groups (the GPG and the MLEG) were designed by the researcher, piloted, and revised. The meditational materials for each intervention program comprised of a reading comprehension test and the Mediated Learning Experience Taxonomy (The MLET) for the MLE intervention program and the Graduated Prompt Moves Protocol (GPMP) for GP group. The MLET was not generated a priori but instead the MLET was produced as the result of the careful analysis of the mediator's cooperative dialogues with each of the learners in every session. In this way, the MLET was developed in a manner parallel to the Regulatory Scale reported in Aljaafreh and Lantolf (1994). Following Aljaafreh and Lantolf, the MLET presented in 
Appendix 1, was not meant to be exhaustive and to be prescriptive. In fact, in line with Poehner (2005), the MLET only described the mediator-learner interactions in the present study but should not be viewed as rules, or, norms. Generally, one of the specific features of the interactionist (MLE) DA, according to Feuerstein, Rand and Rynders (1988, as cited in Poehner, 2005) is proving the flexible grounds in which the learner development can be enhanced well. Producing the meditational taxonomy provided the researcher with a criterion for comparing and analyzing the quality and the frequency of the mediations delivered and used by the learners during the MLE intervention program.

GPMP for GP group (Appendix 2) was based on Brown's GP. Brown's GP, according to Campione et al. (1984), refers to the fixed menu of the standardized hints and prompts, moving from the most implicit to the most explicit one and ending up with the correct answer. In Brown's GP, unlike to the MLE approach, the hierarchies of the assistance are worked out in advance of assessments. Accordingly, the mediation typology in the GP approach is generated a priori and then applied during DA sessions. The meditational inventory for the GP intervention program in this study was then carefully produced prior to the intervention program. More importantly, the explicitness of each prompt was carefully examined during the pilot study.

\subsection{Procedure}

In order to investigate the adequacy of the instruments used, a pilot study preceded the main study. It was also intended to gather a valid repertoire of the mediational taxonomies for the intervention programs. The study in each semester lasted 9 weeks, including the time required for administering the assessment measures and the intervention sessions. The overview of the main study procedure is shown in Table 1 .

Table 1. An Overview of the Main Study Procedure

\begin{tabular}{lll}
\hline Week & Experimental Groups the MLEG \& the GPG & The CG \\
\hline 1 & Introduction to the program and course & Introduction to the program \\
2 & KET & KET \\
3 & Pretest and CMSQ & Pretest and CMSQ \\
4 & Semi-Structured interview & $*$ \\
5 & Intervention session 1 & $*$ \\
& For MLEG, MLET was applied & \\
6 & For GPG, GPMP was applied & $*$ \\
& Intervention session 2 & \\
7 & For MLEG, MLET was applied & $*$ \\
& For GPG, GPMP was applied & \\
8 & Intervention session3 & Por MLEG, MLET was applied \\
9 & For GPG, GPMP was applied & Transfer Test \\
\hline CG wastest & Transfer Test
\end{tabular}

A thorough and precise time management for the total of 170 private sessions with MLEG and a total of 170 private sessions with GPG was certainly required.

2.3.1 The first intervention program: Feuerstein's MLE approach. This program was employed for the MLEG. The program was inspired by Feuerstein's MLE and had the express purpose of remediating those areas in the learner's performance that had been found, through the initial assessments, to be in the need of attention. The interactions between the mediator and the learners during the intervention sessions were a continuation of three sessions of working on three specific domains of reading comprehension in each session. The mediations with which the learners were provided were sensitive to their ZPD and thus were intended to promote development.

2.3.2 The second intervention program: Brown's GP. This program was employed in the intervention sessions with the GPG. The program was inspired by Brown's GP approach of DA. The graduated prompting process of the assessment utilizes ZPD to predict learner's readiness to learn or to reinforce the benefits of the instruction. The Brown's GP procedure, unlike Feuerstein's mediational procedure, is standardized so as to produce the quantitative data. The main difference between Feuerstein's MLE and Brown's GP is in the hierarchies of assistance provided during the intervention sessions. In GP approach, the hierarchies of the assistance are worked out in advance of the assessments. Therefore, it is the significant feature in the GP model of DA to generate the mediational typology a priori. To this aim, a protocol of the rules and mediations for each domain of reading comprehension was developed prior to the GP intervention program.

Similar to the MLE intervention program, the interactions between the mediator and the learners during the GP intervention program were also a continuation of three sessions of working on three specific domains of reading comprehension in each session. The mediations provided for learners were sensitive to their ZPD and thus was intended to promote development. A major requisite for the GP approach, in keeping with Poehner's (2005) line of reasoning, is sticking to the "prepared prompt framework and use the same mediation with every learner and move through their 
scales of assistance in precisely the same order so as to preserve the standardization of the procedure, which enables use of inferential statistical analysis"(p. 162). Therefore, the GPMP was strictly followed during the GP intervention sessions.

\section{Results and Discussion}

It should be noted that, because of brevity, the qualitative data analyses will not be included in this paper. The quantitative methods were used in order to investigate the "product" of reading comprehension whereas the qualitative methods targeted at the "process" of reading comprehension which involves the report of the results of the grounded analyses of the data collected during the semi structured-interview and the intervention programs carried out in the present study. It should be noted that the results of the quantitative data analyses are reported into two sections of (1) aggregate quantitative data analyses, and (2) disaggregated quantitative data analyses. The aggregate data analysis is based on the participants' independent reading comprehension and is approached by means of descriptive and inferential statistical measures. Disaggregated data analysis examines the raw counts of learners' responses produced for each single domain of reading comprehension to provide deeper insight into the learners' moves.

\subsection{Aggregate Quantitative Data Analyses}

This section presents the results obtained through the quantitative methodologies used in this study. The degree of homogeneity between the MLEG, the GPG and the CG was statistically determined using one way analysis of variance for the continuous variables of the Reading KET, the pretest, and the CMSQ.

Table 2. Descriptive and Inferential Statistics in the Reading KET, the Pretest, and the CMSQ

\begin{tabular}{lllllllll}
\hline Variables & $\begin{array}{l}\text { MLEG } \\
(\mathrm{N}=34)\end{array}$ & & $\begin{array}{l}\text { GPG } \\
(\mathrm{N}=34)\end{array}$ & $\begin{array}{l}\text { CG } \\
(\mathrm{N}=34)\end{array}$ & & $F^{*}$ & Sig. \\
\hline & $\mathrm{M}$ & $\mathrm{SD}$ & $\mathrm{M}$ & $\mathrm{SD}$ & $\mathrm{M}$ & $\mathrm{SD}$ & & \\
Reading KET & 17.38 & 4.06 & 17.29 & 4.97 & 18.06 & 8.87 & 0.239 & 0.78 \\
Pretest & 8.26 & 2.93 & 8.41 & 3.33 & 7.79 & 2.78 & 0.387 & 0.68 \\
CMSQ & 107.47 & 13.27 & 103.03 & 12.47 & 106.26 & 13.72 & 1.021 & 0.364 \\
\hline
\end{tabular}

* $\alpha$ value is significant at $\alpha<0.05$

Actually, the analyses were performed in order to address the selection and regression threats and also to ensure that the GPG, the MLEG, and the CG were initially as homogenous as possible in terms of their general reading comprehension ability (applying the reading KET), specific reading comprehension domains (applying the pretest), and reading comprehension strategy awareness (applying CMSQ). As Table 1 depicts, in the scores of the Reading KET $(\mathrm{M}=$ 17.38, $\mathrm{SD}=4.06 ; \mathrm{M}=17.29, \mathrm{SD}=4.97 ; \mathrm{M}=18.06, \mathrm{SD}=8.87$ ) for the $\mathrm{MLEG}$, the $\mathrm{GPG}$ and the CG respectively, no statistically significant group mean differences were observed and the results of the t-test showed that with the F $(2,99)$ $=0.24, \mathrm{p}=0.78>0.05$, there was no significant differences between the groups in terms of their mean scores.

The results of the descriptive statistical data analyses of the pretest $(\mathrm{M}=8.26, \mathrm{SD}=2.93 ; \mathrm{M}=8.41, \mathrm{SD}=3.33 ; \mathrm{M}=$ $7.79, \mathrm{SD}=2.78$ ) for the MLEG, the GPG and the CG respectively showed that there was no statistically significant group mean differences and the results of the $\mathrm{F}(2,99)=0.387, \mathrm{p}=.68>0.05$, indicated that there was no significant differences between the groups in terms of their mean scores. As for the CMSQ, $(\mathrm{M}=107.47, \mathrm{SD}=13.27 ; \mathrm{M}=103.03$, $\mathrm{SD}=12.47 ; \mathrm{M}=106.26, \mathrm{SD}=13.72$ ) for the $\mathrm{MLEG}$, the $\mathrm{GPG}$, and the $\mathrm{CG}$ respectively there were no significant differences between the mean scores of the three groups were observed. A one-way ANOVA was used to compare the mean scores of the GPG, the MLEG and the CG in reading comprehension posttest.

Table 4. Descriptive Statistics for the Reading Comprehension Posttest for all Groups

\begin{tabular}{lllll}
\hline Group & $\mathrm{N}$ & Mean & Std. Deviation & Std. Error Mean \\
\hline \hline MLEG & 34 & 13.73 & 3.80 & 0.65 \\
GPG & 34 & 12 & 2.86 & 0.49 \\
CG & 34 & 8.23 & 2.76 & 0.47 \\
\hline
\end{tabular}

As the results in Table 4 show, the means and the standard deviations $(\mathrm{M}=13.73, \mathrm{SD}=3.80 ; \mathrm{M}=12, \mathrm{~S}=2.86 ; \mathrm{M}=$ $8.25, \mathrm{SD}=2.76$ ) of the MLEG, the GPG, and the CG respectively manifest that all the participants' scores improved from the pretest to the posttest. The results of one way ANOVA is provided in Table 5 .

Table 5. One way ANOVA Comparing Scores for the MLEG, the GPG and the CG in the Posttest

\begin{tabular}{llllll}
\hline & Sum of the Squares & Df & Mean Square & F & Sig. \\
\hline \hline Between Group Variances & 537.59 & 2 & 268.80 & 26.64 & 0.00 \\
Within Group Variances & 998.74 & 99 & 10.08 & & \\
Total & 1536.34 & 101 & & & \\
\hline
\end{tabular}


The F-observed value for comparing the mean scores of three groups in reading comprehension posttest (shown in Table 5) $(\mathrm{F}(2,99)=26.64, \mathrm{P}=0.00<0.05, \eta 2=0.34)$, denoted the significant differences between the mean scores of three groups. In addition, $\eta 2=0.34$ reveals a large effect size. The results of post-hoc Scheffe's tests which were conducted to locate the exact places of the differences between the group means are presented in Table 6.

Table 6. Scheffe's Test for the Posttest for Three Groups

\begin{tabular}{lllll}
\hline Group I & Group J & Mean Differences (I-J) & Std. Error & Sig. \\
\hline \hline GPG & MLEG & -1.73 & 0.78 & 0.08 \\
GPG & CG & $3.76^{*}$ & 0.78 & 0.00 \\
MLEG & CG & $5.50^{*}$ & 0.78 & 0.00 \\
\hline
\end{tabular}

The results presented in Table 6 depicts that the difference between the mean scores of the MLEG and GPG was not statistically significant. There are significant difference between the mean scores of the GPG $(M=12)$ and the $C G(M=$ 8.23 ) in the reading comprehension posttest (Mean difference $=3.76, \mathrm{p}=0.00<0.05$ ). The GPG outperformed the CG in the reading comprehension posttest. In other words, the difference observed between the sample means was large enough to be attributed to the differences between the population means; therefore, the difference was not due to the sampling errors. In fact, the GP approach of DA does intensely affect the participants' reading comprehension in the GPG. In order to assess the strength of the generalization of the findings, the effect size was calculated. The effect size was then estimated and it was 0.34 . Following Cohen (1988, p. 531), this effect size is considered a large effect size.

Given the homogeneity of the GPG and the CG in terms of the reading comprehension ability and strategy awareness at the outset of the study, the dramatic improvement on the GPG's reading comprehension over those of the CG in the posttest, which was conducted after the GP intervention program, could be attributed to the effects of the GP interventions. This is in line with the results of Hayes' (2011) study of applying GP in language learning. GP procedures used by Hayes similarly revealed the participants' learning potential. The results were also in line with Brown and her colleagues' works who devised GP procedures for specific content domains, focusing especially on learners 'reading comprehension as it was reported in Campione et al., (1984). The study also resulted in improvement in the learners' initial posttest scores. The significance of the improvement of the MLEG over the CG in the posttest can be simply associated with the substantial impact of the interventions during the MLE intervention program. As Feuerstein (2000) pinpoints, an absence of MLE will create an individual who will have very little advantage while facing problems with the learning tasks. This result coincided with the results of Lidz's (2002) study. Lidz incorporated MLE into testing practices to define a new addition to the assessment repertory called DA. Lidz similarly concludes that interactions that follow the MLE model produce higher levels of functioning in learners, differentiate responsiveness of learners to intervention and connect assessment and instruction. Lidz also pinpoints that students who experience meditational environments have enhanced chances of improving higher mental functioning and enhancing their competence.

In fact, the students in MLEG outperformed the students in GPG in the posttest. Although Brown and Campione (1985) emphasize on the effects of providing the learner with gradual aids in the learners' progress, regarding the types and the quality of the assistance both groups (the MLEG and the GPG) were provided during the intervention programs, the outperformance of the MLEG over the GPG could be associated with the qualitatively different mediations the MLEG had been offered.

In order to answer the third research question, investigating whether the participants were able to transfer the learned materials during the intervention program to the new situation, the transfer test was administered. Then, in order to compare the mean scores of three groups of the MLEG, the GPG, and the CG in the transfer test, a one-way ANOVA was run (Table 7).

Table 7. Descriptive Statistics for the Reading Comprehension Transfer Test for Three Groups

\begin{tabular}{lllll}
\hline Group & $\mathrm{N}$ & Mean & Std. Deviation & Std. Error Mean \\
\hline \hline MLEG & 34 & 15.59 & 3.76 & 0.65 \\
GPG & 34 & 13.92 & 3.03 & 0.52 \\
CG & 34 & 6.62 & 2.09 & 0.39 \\
\hline
\end{tabular}

The results indicate the mean and the standard deviation of the transfer test $(M=15.58, S D=3.75 ; M=13.91, S=3.02$; $M=6.61, S D=2.08)$, comparing with their mean score and SD in the posttest $(M=13.73, S D=3.80 ; M=12.00, S=$ 2.86; $M=8.25, S D=2.76$ ) for the MLEG, the GPG and the CG, respectively, the MLEG and the GPG's mean scores promoted significantly from the posttest to the transfer test. However, no improvement on the part of the CG's transfer test was observed in Table 7. The results were further studied applying a one way ANOVA (Table 8). 
Table 8. One way ANOVA Comparing the Scores of Three Groups in the Transfer Test

\begin{tabular}{llllll}
\hline & $\begin{array}{l}\text { Sum Of } \\
\text { Squares }\end{array}$ & & & Mean Square F & Sig. \\
\hline \hline Between Group Variances & 1546.84 & 2 & 77.42 & 84.05 & 0.00 \\
Within Group Variances & 911 & 99 & 9.20 & & \\
Total & 2457.85 & 101 & & & \\
\hline
\end{tabular}

The F value of 84.04 denotes the significant differences between the mean scores of the three groups in the transfer test. The post-hoc Scheffe's tests (Table 9) were also conducted to locate the exact places of differences between the three means.

Table 9. Scheffe's Test for the Transfer Test Scores

\begin{tabular}{lllll}
\hline Group I & Group J & $\begin{array}{l}\text { Mean Differences } \\
(\mathrm{I}-\mathrm{J})\end{array}$ & $\begin{array}{l}\text { Std. } \\
\text { Error }\end{array}$ & Sig. \\
\hline \hline GP & MLE & -1.67 & 0.74 & 0.08 \\
GP & CG & 7.29 & 0.743 & 0.00 \\
MLE & CG & 8.97 & 0.74 & 0.00 \\
\hline
\end{tabular}

There is a significant difference between the mean scores of the GPG $(M=13.91)$ and the CG $(M=6.61)$ in the transfer test (Mean difference $=7.29, p=0.00<0.05$ ). Therefore, the GPG outperformed the CG. The transfer test was conducted in an individualized format (private sessions). That is, in order to trace carefully whether the learners were able to apply the strategies learned during the intervention sessions, while doing a new test which was rather more difficult than the posttest, the transfer test was carried out in a one-to-one format. Therefore, the researcher was able to observe the learners' performances while asking them to think aloud. In fact, think-aloud protocols provide a direct view of the reader's mental activity and also offer a kind of window into those processes which are usually hidden (Block, 1986). The learners' ability to use the acquired strategies was directly observed by the researcher.

The approach of extending learning beyond the initial assessment tasks which is the hallmark of Brown's GP approach (Brown \& Campione, 1985), is referred to as transfer in Feuerstein's MLE (Feuerstein, 2000) and it was introduced into the applied linguistics by Poehner (2008). In fact, the findings of Poehner's (2005) study confirmed the importance of the transfer assessments with more complex tasks. Accordingly, the results, in line with Poehner (2005), explore the extent to which the learners were able to extend their ability while doing tests in new and more challenging tasks. Therefore, the present study in combination with the Ferrara, Brown \& Campione's (1986) study, provide strong evidence that DA of learning and transfer efficiency can supplement the information regarding a person's potential that is indicated by static measures of ability.

Furthermore, the profile plot (Figure 1) demonstrates the estimated marginal means of performances of all participants in three groups of the MLEG, the GPG, and the CG, in all three tests conducted.

\section{Estimated Marginal Means of MEASURE_1}

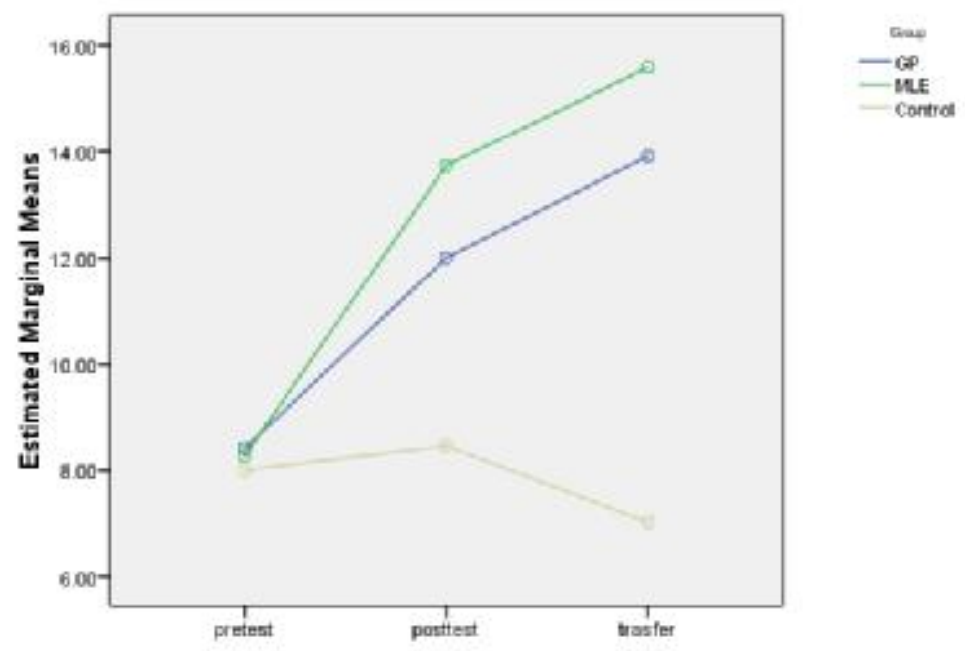

Figure 1. Profile Plots for the Mean Scores of the Reading Comprehension Pretest, Posttest, and Transfer Test 


\subsection{Disaggregated Quantitative Data Analysis}

Disaggregated data analyses simply mean looking at the subsections of the test scores.

\subsection{MLE disaggregated quantitative data analysis}

As it was stated earlier in this study, the reading comprehension tests aimed at testing only three domains of reading comprehension. Therefore, reading comprehension questions were included three subsections of the MQs, the GQs, and the IQs.

Table 10 represents the scores of the MLEG ( $=34$, From Student 35 - Student 68 ). In fact, the students were named with numbers not names.) in three reading comprehension tests. The 24 item reading tests consist of four MQs, eight GQs, and twelve IQs. The scores recorded in each cell indicate the number of the correct responses for each item. Table 10 shows dramatic improvement of S35 in the GQs in the posttest and the transfer test: $4 \rightarrow 6$ in the posttest and $6 \rightarrow 8$ in the transfer test. By comparing the students' scores and their performance in each domain of reading comprehension tested by three reading tests, the students' improvement in the posttest and, in turn, in the transfer test are quite evident.

Student 45 's marked improvement in the MQs is shown in Table $10(0 \rightarrow 4 \rightarrow 4)$. She scored 0 in the pretest indicating that she could not answer any of the MQs. Though, she answered all four MQs in the posttest correctly. More importantly, S45 could transfer the acquired knowledge onto novel test of the transfer test and she also scored four in the transfer test. Her scores in the GQs and the IQs also uncovered her dramatic progress: $2 \rightarrow 5 \rightarrow 5$ and $4 \rightarrow 8 \rightarrow 8$ in posttest and transfer test, respectively. In addition, S47 also showed marked improvement in the IQs: $4 \rightarrow 7 \rightarrow 10$. The results became patently clear when a percentage was calculated. Table 10 represents the percentages of the scores.

Table 10. The MLEG's Scores in all Three Reading Comprehension Domains across three administration.

\begin{tabular}{|c|c|c|c|c|c|c|c|c|c|}
\hline $\mathrm{Sn}$ & \begin{tabular}{|l} 
Pretest \\
Total $=4$
\end{tabular} & $\begin{array}{l}\text { MQs } \\
\text { Posttest } \\
\text { Total=4 }\end{array}$ & $\begin{array}{l}\text { Transfer Test } \\
\text { Total }=4\end{array}$ & $\begin{array}{l}\text { pretest } \\
\text { Total }=8\end{array}$ & $\begin{array}{l}\text { GQs } \\
\text { Posttest } \\
\text { Total=8 }\end{array}$ & $\begin{array}{l}\text { Transfer Test } \\
\text { Total }=8\end{array}$ & $\begin{array}{l}\text { Pretest } \\
\text { Total }=12\end{array}$ & $\begin{array}{l}\text { IQs } \\
\text { Posttest } \\
\text { Total=12 }\end{array}$ & $\begin{array}{l}\text { Transfer Test } \\
\text { Total }=12\end{array}$ \\
\hline 35 & 2 & 3 & 3 & 4 & 6 & 8 & 6 & 7 & 7 \\
\hline 36 & 1 & 3 & 3 & 4 & 7 & 6 & 3 & 4 & 6 \\
\hline 37 & 1 & 2 & 2 & 4 & 7 & 7 & 5 & 7 & 8 \\
\hline 38 & 1 & 4 & 4 & 2 & 3 & 2 & 1 & 1 & 3 \\
\hline 39 & 0 & 2 & 2 & 2 & 4 & 5 & 2 & 2 & 2 \\
\hline 40 & 0 & 2 & 2 & 2 & 4 & 5 & 3 & 3 & 8 \\
\hline 41 & 1 & 3 & 3 & 2 & 4 & 4 & 2 & 3 & 4 \\
\hline 42 & 2 & 3 & 3 & 2 & 4 & 4 & 2 & 3 & 5 \\
\hline 43 & 0 & 3 & 2 & 2 & 4 & 6 & 4 & 6 & 5 \\
\hline 44 & 1 & 2 & 2 & 3 & 5 & 6 & 2 & 3 & 2 \\
\hline 45 & 0 & 4 & 4 & 2 & 5 & 5 & 4 & 8 & 8 \\
\hline 46 & 1 & 2 & 3 & 1 & 5 & 6 & 4 & 3 & 3 \\
\hline 47 & 0 & 4 & 4 & 1 & 6 & 7 & 5 & 9 & 10 \\
\hline 48 & 1 & 3 & 2 & 4 & 2 & 6 & 2 & 4 & 3 \\
\hline 49 & 1 & 2 & 2 & 1 & 3 & 4 & 5 & 4 & 6 \\
\hline 50 & 1 & 3 & 3 & 4 & 5 & 7 & 2 & 7 & 5 \\
\hline 51 & 1 & 4 & 4 & 2 & 4 & 6 & 4 & 8 & 8 \\
\hline 52 & 1 & 3 & 3 & 3 & 5 & 7 & 4 & 2 & 7 \\
\hline 53 & 3 & 4 & 4 & 3 & 4 & 6 & 2 & 9 & 9 \\
\hline 54 & 1 & 3 & 3 & 5 & 5 & 8 & 3 & 8 & 5 \\
\hline 55 & 2 & 2 & 2 & 3 & 4 & 7 & 4 & 7 & 10 \\
\hline 56 & 1 & 4 & 3 & 3 & 4 & 6 & 5 & 2 & 7 \\
\hline 57 & 1 & 4 & 4 & 4 & 4 & 3 & 4 & 2 & 4 \\
\hline 58 & 2 & 2 & 4 & 3 & 5 & 4 & 5 & 7 & 7 \\
\hline 59 & 1 & 4 & 4 & 4 & 6 & 7 & 5 & 10 & 9 \\
\hline 60 & 2 & 2 & 3 & 3 & 4 & 6 & 7 & 9 & 11 \\
\hline 61 & 1 & 4 & 4 & 5 & 6 & 8 & 4 & 8 & 8 \\
\hline 62 & 1 & 2 & 4 & 5 & 7 & 7 & 5 & 7 & 7 \\
\hline 63 & 2 & 3 & 3 & 2 & 6 & 8 & 7 & 10 & 9 \\
\hline 64 & 0 & 2 & 3 & 2 & 4 & 6 & 2 & 3 & 3 \\
\hline 65 & 2 & 4 & 4 & 5 & 7 & 7 & 7 & 7 & 8 \\
\hline 66 & 2 & 2 & 3 & 4 & 7 & 8 & 9 & 9 & 9 \\
\hline 67 & 0 & 2 & 3 & 2 & 3 & 7 & 5 & 7 & 8 \\
\hline 68 & 3 & 3 & 4 & 4 & 6 & 7 & 8 & 11 & 11 \\
\hline
\end{tabular}

*Sn: The student's number, MQs: Main Idea Questions, GQs: Guessing the meaning of the new words Questions, IQs: Inferencing Questions.

As it is evident in Table 11, for majority of the learners the scores rose dramatically from the pretest to the posttest. For instance, in the case of S63 her GQs' scores rose from $25 \%$ to $75 \%$ in the posttest and she could maintain this progress in the transfer test (100\%). Regarding the IQs, in the case of S47, her score rose from $41.66 \%$ in the pretest to $75 \%$ in the posttest. 
The S47's percentage score in the transfer test demonstrated that she was able to use the acquired knowledge in the novel context of the transfer test as her scored rose from $75 \%$ in the posttest to $83.33 \%$ in the transfer test. Examining the concept of transcendence in DA, many instances can be easily traced in Table 10. (e.g. S52's GQs and IQs scores, S67's MQs, GQs, and IQs scores).

However, in a few instances, the learners' scores demonstrated no progress or even reduction in the posttest and transfer test. For example, although S36's MQs' scores rose from the pretest to posttest ( $25 \%$ to $75 \%$ ), her score did not improve from the posttest to the transfer test. Similar results can be seen with S58's IQs' scores $(41.66 \%, 58.33 \%$ and $58.33 \%$ in the pretest, posttest and transfer test respectively). A few reductions are also observed. For example, S63'S IQs' scores demonstrated reduction from the posttest to the transfer test following a dramatic increase from the pretest to the posttest $(58.33 \%, 83.33 \%$, and $75 \%$ in the pretest, posttest and transfer test, respectively).

Table 11. The Percentage of the MLEG's Scores in all Three Reading Comprehension Domains across three administration

\begin{tabular}{|c|c|c|c|c|c|c|c|c|c|}
\hline Sn & $\begin{array}{l}\text { Pretest } \\
\text { Total }=4\end{array}$ & $\begin{array}{l}\text { MQs } \\
\text { Posttest } \\
\text { Total=4 }\end{array}$ & $\begin{array}{l}\text { Transfer Test } \\
\text { Total }=4\end{array}$ & $\begin{array}{l}\text { pretest } \\
\text { Total }=8\end{array}$ & $\begin{array}{l}\text { GQs } \\
\text { Posttest } \\
\text { Total }=8\end{array}$ & $\begin{array}{l}\text { Transfer Test } \\
\text { Total }=8\end{array}$ & $\begin{array}{l}\text { Pretest } \\
\text { Total }=12\end{array}$ & $\begin{array}{l}\text { IQs } \\
\text { Posttest } \\
\text { Total=12 }\end{array}$ & $\begin{array}{l}\text { Transfer Test } \\
\text { Total }=12\end{array}$ \\
\hline$\overline{35}$ & $50 \%$ & $75 \%$ & $75 \%$ & $50 \%$ & $75 \%$ & $100 \%$ & $50 \%$ & $58.33 \%$ & $58.33 \%$ \\
\hline 36 & $25 \%$ & $75 \%$ & $75 \%$ & $50 \%$ & $87.5 \%$ & $75 \%$ & $25 \%$ & $33.33 \%$ & $50 \%$ \\
\hline 37 & $25 \%$ & $50 \%$ & $50 \%$ & $50 \%$ & $87.5 \%$ & $87.5 \%$ & $41.66 \%$ & $58.33 \%$ & $66.66 \%$ \\
\hline 38 & $25 \%$ & $100 \%$ & $100 \%$ & $25 \%$ & $37.5 \%$ & $25 \%$ & $8.33 \%$ & $8.33 \%$ & $25 \%$ \\
\hline 39 & $0 \%$ & $50 \%$ & $50 \%$ & $25 \%$ & $50 \%$ & $62.5 \%$ & $16.66 \%$ & $16.66 \%$ & $16.66 \%$ \\
\hline 40 & $0 \%$ & $50 \%$ & $50 \%$ & $25 \%$ & $50 \%$ & $62.5 \%$ & $25 \%$ & $25 \%$ & $66.66 \%$ \\
\hline 41 & $25 \%$ & $75 \%$ & $75 \%$ & $25 \%$ & $50 \%$ & $50 \%$ & $16.66 \%$ & $25 \%$ & $33.33 \%$ \\
\hline 42 & $50 \%$ & $75 \%$ & $75 \%$ & $25 \%$ & $50 \%$ & $50 \%$ & $16.66 \%$ & $25 \%$ & $41.66 \%$ \\
\hline 43 & $0 \%$ & $75 \%$ & $50 \%$ & $25 \%$ & $50 \%$ & $75 \%$ & $33.33 \%$ & $50 \%$ & $41.66 \%$ \\
\hline 44 & $25 \%$ & $50 \%$ & $50 \%$ & $37.5 \%$ & $62.5 \%$ & $75 \%$ & $16.66 \%$ & $25 \%$ & $16.66 \%$ \\
\hline 45 & $0 \%$ & $100 \%$ & $100 \%$ & $25 \%$ & $62.5 \%$ & $62.5 \%$ & $33.33 \%$ & $66.66 \%$ & $66.66 \%$ \\
\hline 46 & $25 \%$ & $50 \%$ & $75 \%$ & $12.5 \%$ & $62.5 \%$ & $75 \%$ & $33.33 \%$ & $25 \%$ & $25 \%$ \\
\hline 47 & $0 \%$ & $100 \%$ & $100 \%$ & $12.5 \%$ & $75 \%$ & $87.5 \%$ & $41.66 \%$ & $75 \%$ & $83.33 \%$ \\
\hline 48 & $25 \%$ & $75 \%$ & $50 \%$ & $50 \%$ & $25 \%$ & $75 \%$ & $16.66 \%$ & $33.33 \%$ & $25 \%$ \\
\hline 49 & $25 \%$ & $50 \%$ & $50 \%$ & $12.5 \%$ & $37.5 \%$ & $50 \%$ & $41.66 \%$ & $33.33 \%$ & $50 \%$ \\
\hline 50 & $25 \%$ & $75 \%$ & $75 \%$ & $50 \%$ & $62.5 \%$ & $87.5 \%$ & $16.66 \%$ & $58.33 \%$ & $41.66 \%$ \\
\hline 51 & $25 \%$ & $100 \%$ & $100 \%$ & $25 \%$ & $50 \%$ & $75 \%$ & $33.33 \%$ & $66.66 \%$ & $66.66 \%$ \\
\hline 52 & $25 \%$ & $75 \%$ & $75 \%$ & $37.5 \%$ & $62.5 \%$ & $87.5 \%$ & $33.33 \%$ & $16.66 \%$ & $58.33 \%$ \\
\hline 53 & $75 \%$ & $100 \%$ & $100 \%$ & $37.5 \%$ & $50 \%$ & $75 \%$ & $16.66 \%$ & $75 \%$ & $75 \%$ \\
\hline 54 & $25 \%$ & $75 \%$ & $75 \%$ & $62.5 \%$ & $62.5 \%$ & $100 \%$ & $25 \%$ & $66.66 \%$ & $41.66 \%$ \\
\hline 55 & $50 \%$ & $50 \%$ & $50 \%$ & $37.5 \%$ & $50 \%$ & $87.5 \%$ & $33.33 \%$ & $58.33 \%$ & $83.33 \%$ \\
\hline 56 & $25 \%$ & $100 \%$ & $75 \%$ & $37.5 \%$ & $50 \%$ & $75 \%$ & $41.66 \%$ & $16.66 \%$ & $58.33 \%$ \\
\hline 57 & $25 \%$ & $100 \%$ & $100 \%$ & $50 \%$ & $50 \%$ & $37.5 \%$ & $33.33 \%$ & $16.66 \%$ & $33.33 \%$ \\
\hline 58 & $50 \%$ & $50 \%$ & $100 \%$ & $37.5 \%$ & $62.5 \%$ & $50 \%$ & $41.66 \%$ & $58.33 \%$ & $58.33 \%$ \\
\hline 59 & $25 \%$ & $100 \%$ & $100 \%$ & $50 \%$ & $75 \%$ & $87.5 \%$ & $41.66 \%$ & $83.33 \%$ & $75 \%$ \\
\hline 60 & $50 \%$ & $50 \%$ & $75 \%$ & $37.5 \%$ & $50 \%$ & $75 \%$ & $58.33 \%$ & $75 \%$ & $91.66 \%$ \\
\hline 61 & $25 \%$ & $100 \%$ & $100 \%$ & $62.5 \%$ & $75 \%$ & $100 \%$ & $33.33 \%$ & $66.66 \%$ & $66.66 \%$ \\
\hline 62 & $25 \%$ & $50 \%$ & $100 \%$ & $62.5 \%$ & $87.5 \%$ & $87.5 \%$ & $41.66 \%$ & $58.33 \%$ & $58.33 \%$ \\
\hline 63 & $50 \%$ & $75 \%$ & $75 \%$ & $25 \%$ & $75 \%$ & $100 \%$ & $58.33 \%$ & $83.33 \%$ & $75 \%$ \\
\hline 64 & $0 \%$ & $50 \%$ & $75 \%$ & $25 \%$ & $50 \%$ & $75 \%$ & $16.66 \%$ & $25 \%$ & $25 \%$ \\
\hline 65 & $50 \%$ & $100 \%$ & $100 \%$ & $62.5 \%$ & $87.5 \%$ & $87.5 \%$ & $58.33 \%$ & $58.33 \%$ & $66.66 \%$ \\
\hline 66 & $50 \%$ & $50 \%$ & $75 \%$ & $50 \%$ & $87.5 \%$ & $100 \%$ & $75 \%$ & $75 \%$ & $75 \%$ \\
\hline 67 & $0 \%$ & $50 \%$ & $75 \%$ & $25 \%$ & $37.5 \%$ & $87.5 \%$ & $41.66 \%$ & $58.33 \%$ & $66.66 \%$ \\
\hline 68 & $75 \%$ & $75 \%$ & $100 \%$ & $50 \%$ & $75 \%$ & $87.5 \%$ & $66.66 \%$ & $91.66 \%$ & $91.66 \%$ \\
\hline
\end{tabular}

*Sn: The student's number, MQs: Main Idea Questions, GQs: Guessing the meaning of the new words Questions, IQs: Inferencing Questions

\subsection{GP disaggregated quantitative data analysis}

The primary measures of interest in this study for the GP intervention program was the number of the prompts a learner required to reach the learning criterion in each intervention session. Table 12 presents the number of the prompts each learner was required to arrive at the correct response for each item in GPG.

Table 12 shows the number of the prompts each student received to find the correct response for each question during the GP intervention sessions. The scores the GPG gained from the pretest to the posttest range from 0 to 10 . According to the results shown in Table 12, S9 gained the highest score (i.e. 10). She improved dramatically from the pretest to the posttest following the intervention program. S1, who gained 9 scores in the posttest, comes after S9. Her reading comprehension performance also showed great progress from the pretest to the posttest after the program. In contrast, S15 who did not gain any scores in the posttest, indicating no improvement, is placed at the end of the list in Table 12. 


\begin{tabular}{|c|c|c|c|c|c|c|c|c|c|c|c|c|c|c|c|c|c|c|c|c|c|c|c|}
\hline \multicolumn{24}{|l|}{ HGs } \\
\hline S9 & 10 & 3 & 2 & 1 & 0 & 3 & 3 & 3 & 2 & 2 & 0 & 4 & 4 & 3 & 3 & 3 & 2 & 3 & 3 & 3 & 3 & 2 & 1 \\
\hline S1 & 9 & 3 & 2 & 1 & 1 & 2 & 2 & 2 & 1 & 1 & 0 & 5 & 4 & 3 & 3 & 2 & 1 & 4 & 3 & 3 & 2 & 2 & 2 \\
\hline $\mathrm{S} 10$ & 8 & 3 & 3 & 2 & 1 & 3 & 2 & 2 & 2 & 1 & 1 & 4 & 3 & 3 & 3 & 2 & 2 & 3 & 3 & 2 & 2 & 1 & 1 \\
\hline S18 & 7 & 3 & 2 & 1 & 1 & 4 & 3 & 3 & 2 & 1 & 0 & 4 & 3 & 3 & 3 & 2 & 2 & 4 & 3 & 3 & 2 & 2 & 1 \\
\hline $\mathrm{S} 2$ & 6 & 3 & 2 & 2 & 1 & 2 & 2 & 1 & 1 & 1 & 0 & 5 & 3 & 3 & 3 & 2 & 2 & 3 & 2 & 2 & 2 & 1 & 0 \\
\hline S4 & 6 & 3 & 3 & 1 & 0 & 3 & 3 & 3 & 2 & 2 & 1 & 3 & 3 & 3 & 2 & 2 & 2 & 3 & 2 & 2 & 2 & 2 & 2 \\
\hline S7 & 5 & 3 & 2 & 2 & 1 & 3 & 3 & 2 & 2 & 1 & 0 & 4 & 3 & 3 & 2 & 1 & 1 & 3 & 3 & 3 & 2 & 2 & 2 \\
\hline S20 & 5 & 4 & 3 & 2 & 1 & 4 & 3 & 3 & 2 & 2 & 1 & 4 & 4 & 4 & 3 & 2 & 2 & 3 & 2 & 2 & 2 & 0 & 0 \\
\hline $\mathrm{S} 26$ & 5 & 3 & 2 & 2 & 0 & 3 & 3 & 2 & 2 & 2 & 2 & 3 & 3 & 3 & 3 & 2 & 2 & 3 & 3 & 2 & 2 & 2 & 2 \\
\hline \multicolumn{24}{|c|}{$\overline{\mathrm{MGs}}$} \\
\hline S5 & 4 & 4 & 3 & 2 & 1 & 4 & 3 & 3 & 3 & 2 & 2 & 3 & 4 & 3 & 3 & 3 & 3 & 4 & 3 & 4 & 3 & 2 & 0 \\
\hline S6 & 4 & 3 & 2 & 2 & 0 & 3 & 3 & 2 & 2 & 2 & 1 & 4 & 3 & 4 & 2 & 4 & 3 & 4 & 3 & 4 & 3 & 3 & 3 \\
\hline S11 & 4 & 3 & 3 & 1 & 1 & 3 & 3 & 2 & 2 & 1 & 0 & 4 & 4 & 3 & 3 & 4 & 2 & 3 & 4 & 3 & 3 & 4 & 2 \\
\hline $\mathrm{S} 12$ & 4 & 3 & 2 & 2 & 2 & 3 & 4 & 3 & 3 & 2 & 3 & 4 & 3 & 3 & 3 & 2 & 2 & 4 & 3 & 3 & 3 & 2 & 0 \\
\hline S17 & 4 & 4 & 1 & 1 & 0 & 3 & 4 & 3 & 4 & 3 & 3 & 3 & 3 & 4 & 3 & 4 & 3 & 3 & 3 & 3 & 4 & 3 & 3 \\
\hline $\mathrm{S} 3$ & 3 & 3 & 1 & 3 & 2 & 3 & 4 & 4 & 3 & 2 & 3 & 3 & 3 & 3 & 4 & 4 & 3 & 4 & 3 & 4 & 3 & 2 & 3 \\
\hline $\mathrm{S} 23$ & 3 & 3 & 3 & 2 & 3 & 4 & 3 & 4 & 2 & 3 & 1 & 5 & 4 & 3 & 3 & 3 & 4 & 4 & 3 & 4 & 3 & 3 & 3 \\
\hline S27 & 3 & 3 & 2 & 3 & 3 & 3 & 2 & 3 & 1 & 3 & 0 & 4 & 4 & 3 & 4 & 2 & 3 & 3 & 3 & 4 & 3 & 2 & 3 \\
\hline S28 & 3 & 0 & 2 & 2 & 1 & 2 & 3 & 4 & 3 & 3 & 1 & 5 & 3 & 3 & 4 & 3 & 2 & 3 & 3 & 4 & 3 & 2 & 3 \\
\hline S29 & 3 & 2 & 2 & 4 & 1 & 3 & 4 & 3 & 4 & 4 & 2 & 4 & 4 & 3 & 4 & 3 & 2 & 3 & 3 & 3 & 4 & 3 & 2 \\
\hline $\mathrm{S} 30$ & 3 & 2 & 3 & 0 & 3 & 3 & 3 & 4 & 4 & 4 & 0 & 3 & 4 & 3 & 4 & 3 & 3 & 3 & 3 & 4 & 3 & 3 & 2 \\
\hline \multicolumn{24}{|l|}{ LGs } \\
\hline S8 & 2 & 3 & 3 & 2 & 3 & 3 & 4 & 4 & 3 & 4 & 4 & 3 & 4 & 3 & 4 & 3 & 2 & 3 & 4 & 3 & 2 & 2 & 0 \\
\hline $\mathrm{S} 13$ & 2 & 4 & 3 & 4 & 3 & 3 & 4 & 4 & 3 & 3 & 1 & 5 & 4 & 3 & 4 & 3 & 4 & 4 & 4 & 3 & 4 & 3 & 3 \\
\hline S19 & 2 & 2 & 3 & 2 & 3 & 4 & 4 & 3 & 4 & 2 & 0 & 5 & 3 & 4 & 5 & 3 & 4 & 4 & 3 & 3 & 3 & 4 & 3 \\
\hline S21 & 2 & 3 & 3 & 2 & 3 & 4 & 3 & 4 & 3 & 3 & 3 & 4 & 5 & 3 & 4 & 3 & 4 & 4 & 3 & 3 & 4 & 3 & 3 \\
\hline S22 & 2 & 4 & 3 & 4 & 3 & 4 & 4 & 3 & 4 & 3 & 3 & 5 & 3 & 4 & 3 & 5 & 3 & 3 & 4 & 3 & 4 & 3 & 3 \\
\hline S25 & 2 & 4 & 4 & 3 & 3 & 4 & 3 & 3 & 4 & 2 & 3 & 5 & 4 & 5 & 3 & 4 & 4 & 4 & 3 & 3 & 2 & 3 & 3 \\
\hline S31 & 2 & 3 & 4 & 3 & 2 & 3 & 4 & 3 & 4 & 3 & 3 & 4 & 4 & 4 & 3 & 4 & 3 & 3 & 4 & 3 & 2 & 3 & 1 \\
\hline $\mathrm{S} 32$ & 2 & 3 & 2 & 3 & 3 & 3 & 2 & 4 & 3 & 3 & 3 & 4 & 3 & 4 & 5 & 3 & 3 & 3 & 4 & 3 & 4 & 1 & 2 \\
\hline S33 & 2 & 3 & 3 & 3 & 3 & 4 & 3 & 4 & 4 & 3 & 0 & 5 & 5 & 4 & 3 & 4 & 4 & 4 & 3 & 4 & 4 & 2 & 1 \\
\hline S34 & 2 & 3 & 4 & 2 & 3 & 3 & 2 & 3 & 2 & 4 & 3 & 4 & 5 & 3 & 4 & 4 & 3 & 4 & 3 & 4 & 3 & 2 & 1 \\
\hline $\mathrm{S} 14$ & 1 & 3 & 3 & 4 & 2 & 4 & 4 & 3 & 4 & 3 & 4 & 5 & 4 & 4 & 3 & 4 & 3 & 4 & 3 & 4 & 3 & 4 & 2 \\
\hline S16 & 1 & 4 & 3 & 4 & 3 & 3 & 4 & 3 & 3 & 3 & 4 & 4 & 4 & 3 & 4 & 2 & 3 & 4 & 3 & 2 & 3 & 4 & 3 \\
\hline S24 & 1 & 3 & 4 & 3 & 2 & 3 & 3 & 2 & 3 & 3 & 4 & 5 & 5 & 4 & 3 & 4 & 3 & 4 & 3 & 4 & 3 & 2 & 3 \\
\hline$\underline{\mathrm{S} 15}$ & 0 & 3 & 3 & 2 & 3 & 3 & 3 & 4 & 3 & 3 & 4 & 4 & 4 & 4 & 3 & 4 & 3 & 4 & 3 & 4 & 4 & 3 & 3 \\
\hline
\end{tabular}

* Sn: The Student numbers; HGs: High Gainers, MGs: Mid Gainers; LGs: Low Gainers; GS: Stands for Gain Scores; Q: Question, MQP: The number of Prompts for the Main idea Questions; GQPs: The number of Prompts for the Guessing Questions; IQPs: the number of Prompts for the ferencing Questions.

In order to detect the relationship between the students' gain scores in the posttest (the different between the scores in the pretest and posttest) and the number of the prompts they received during the intervention programs, the students were listed based on their gain scores. In other words, S9 who gained the highest scores of 10 is the first in the table, and S15 who did not gain any scores in the posttest is the last person in the table. Therefore, the students were divided into three groups: Those who gained 5-10 scores in the posttest were named as the high gainers, those who gained 3-4 scores were named as the mid gainers, and those who gained only 1-2 or no scores were named as the low gainers.

Apparently, a regular pattern can be observed in the scores of the high gainers. The number of the prompts the high gainers received to find the correct responses manifested a descending order. In other words, these students required less prompts after providing the initial prompts in each domain. For example, for the first GQ (Q1), S10 received three prompts, for Q7 she received two prompts, for Q13, one prompt, and finally she received no prompt for Q19. Consider the following extracts from Table 12:

$$
\begin{array}{lccc}
\text { S9: } & 3210 & 333220 & 443332 \\
\text { S1: } & 3211 & 222110 & 543321 \\
\text { S18: } & 3211 & 433210 & 433322 \\
\text { S2: } & 3221 & 221110 & 533322
\end{array}
$$

433222

433221

322210

Figure 2 and Figure 3 depict the descending order which is observed in the number of prompts S9 and S1 received to answer the GQs. Obviously, a descending order is observed in the number of the prompts S9 and S1 received for the GQs. For the initial Q7, S9 required 3 prompts, but she did not require any prompts to answer Q19 which was the last question in the GQs. 


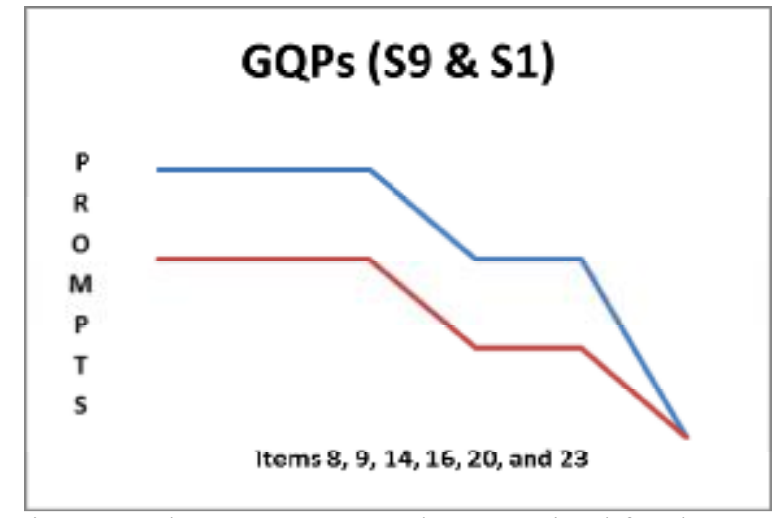

Figure 2. The Prompts S9 and S1 Received for the GQs

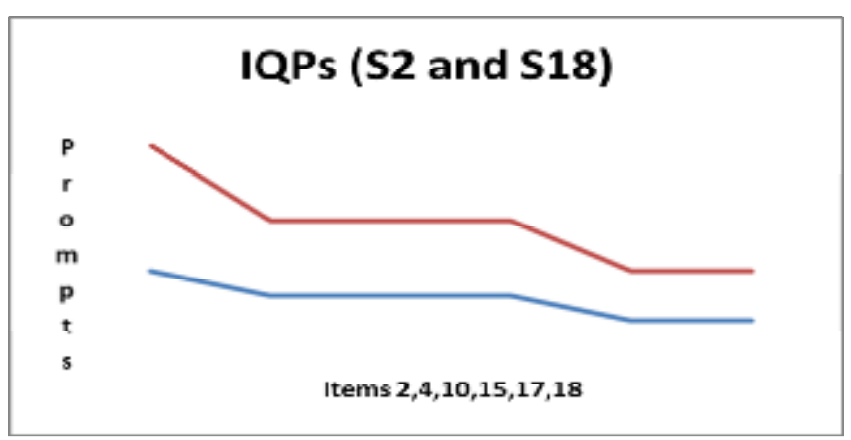

Figure 3. The Prompts S2 and S18 Received for the IQs

On the other hand, this descending order is not observed among the mid gainers and low gainers. Consider the following extracts which were taken from Table 12. The numbers of the prompts received by some mid gainers (S15, S14, and S16) are shown:
S17:
4110
343433
334343
333433
S3: $\quad 3132 \quad 344323$
333443
434323
S23: $3323 \quad 434231 \quad 543334$
434333

As the extracts show, no descending patterns in the prompt numbers are observed. The following extract was taken from the low gainers' prompt numbers (Table 12).
S14: 3342
443434
544343
434342
S24: $3432 \quad 332334$
$554343 \quad 434321$
S15: 3323
334334
444343
434433

As the extracts depict, no declining order in the number of the required prompts are demonstrated. Figures 4 and 5 graphically display the number of the prompts received by some mid gainers and low gainers.

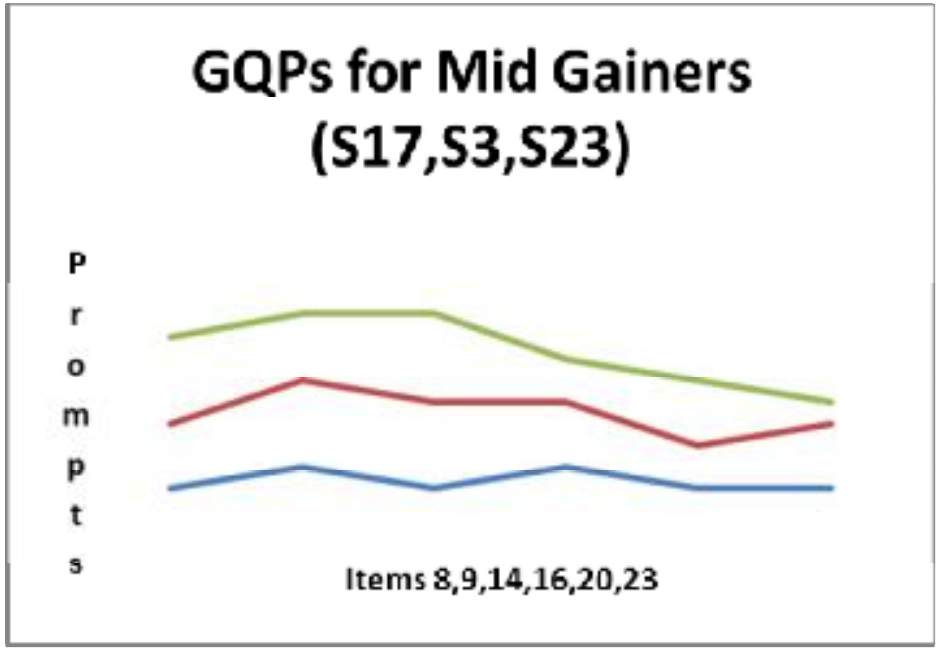

Figure 4. The Prompts Received by S17, S3, and S23for the GQs 


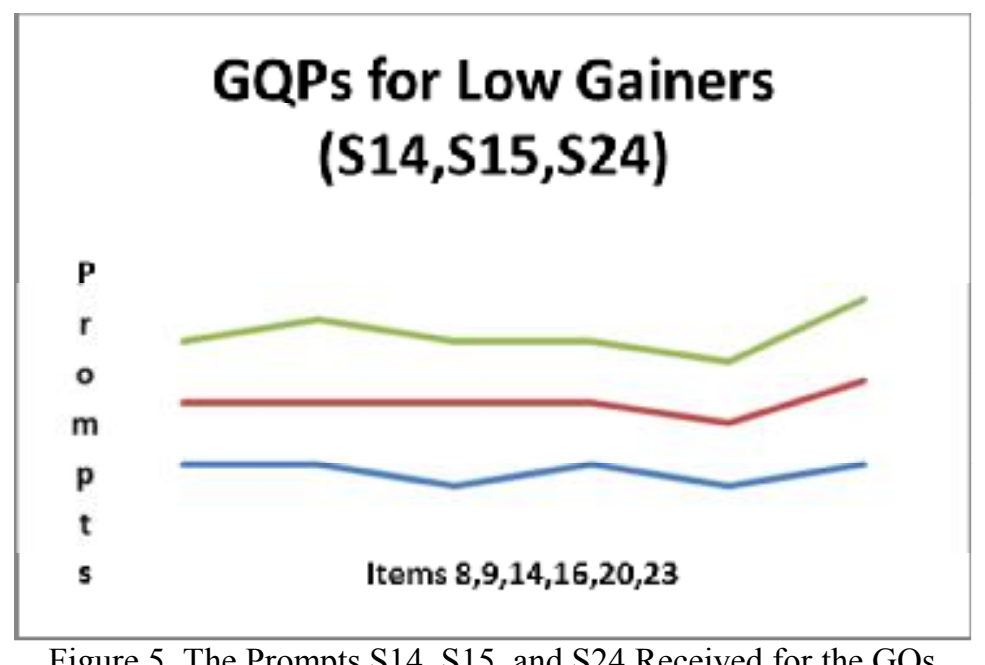

Figure 5. The Prompts S14, S15, and S24 Received for the GQs

Therefore, drawing on the prompts counts presented in Table 12, it can be concluded that the number of the prompts needed for doing a reading test in the GPG is seen as inversely related to learning / transfer ability. In other words, the higher the number of the prompts required to do a test, the less likely it is that the improvement will occur.

\section{Conclusion and implications}

The results of the current study are in concordance with those studies that attempt to investigate the structure of ZPD (e.g., Nassaji \& Cumming, 2000). The implementation of this study, in fact, yields more insights into the regressive and progressive processes associated with the development of $\mathrm{L} 2$ reading comprehension within ZPD. In other words, the findings of the study provide additional support for Vygotsky's ideas about the nature of development.

One of the significant findings of this study is that during the assessment sessions the learners gradually produced more progressive than regressive moves which contribute to a better understanding of the process that pinpoints the transformation of ZPD into the zone of actual development. In addition, the qualitative grounded analyses demonstrated the feasibility of implementing DA in L2 research. The implementation of two DA approaches (GP and MLE) provided more insights into the progressive processes which are associated with the development of L2 reading comprehension within ZPD. These movements are all considered here to be the components of the learners' reading ZPD.

The other sociocultural based implication of the current study is in line with Birjandi and Ebadi (2011), Duvall (2008), Poehner (2005) and many other sociocultural based DA studies. In other words, the findings of the present study are in line with those studies which were based on the grounded analyses of the contextualized learning processes. In fact, the findings showed the power of the grounded analysis to gain L2 developmental processes and provided evidence for the feasibility of such methodology in L2 research.

The findings of this study suggest the implementation of DA approaches for those pedagogical programs targeted at gaining insights into the learners' future development. In other words, a major finding of this study is the learners' progressive movements manifested in the final transfer test results which in turn indicate the transformation of the ZPD into the zone of actual development (the concept which mostly referred to as transcendence by Feuerstein, 2000 and Brown \& Campione, 1985). This is an appropriate response to the problems of the current EAP practices in Iran which are criticized to be "largely ad-hoc, lacking in course design, teacher training, sufficient instruction time, and proper evaluation" (Eslami, 2010, p. 3).

In addition, the taxonomies of the mediational techniques produced in this study (the GPMP and the MLET) enhance the interested DA researchers' understandings of how to offer mediations in EFL classrooms or in particular reading comprehension assessments.

Regarding low language proficiency of Iranian EFL learners (Pourdana, Bornaki, Moayedi Fard, \& Sarkhosh, 2012; Eslami, 2010), reading comprehension assessors are suggested to hold careful attention to the heterogeneity of learners (most specifically in small and to some extent deprived areas) in devising reading comprehension tests. Narrowing reading comprehension domains is consequently recommended. However, the results of the current study suggest language instructors and assessors to identify the appropriate domains of reading for their learners and effectively narrow down the scope of the domains to be more manageable for the short spell of academic semesters prior to any reading programs. In other words, EFL instructors are recommended to abandon quantity in favor of quality.

This study was primarily aimed at exploring as well as comparing the impact of two DA approaches (Brown's GP and Feuerstein's MLE) on EFL learners' reading comprehension. The two models investigated and compared are placed under two umbrella terms of DA, that is, interventionist and interactionist DA approaches, respectively. In short, according to Poehner (2007) interventionists DA devises various means of describing DA interactions, such as scores and counts of mediating moves; however, qualitative profiles of the processes of learners' development are used by interactionist DA. The results of this study suggest that although these approaches have been explained to be qualitatively different, they both produced significant improvement in the learners' reading comprehension. 
However, a significant departure is made if we pay careful attention to the types of mediations provided during the MLE intervention program. In fact, the MLEG's better performance comparing with the performances of GPG in the reading comprehension posttest in the current study, certainly shed light to the recognition of the impact of the different type of mediations in implementation of DA approaches. Therefore, the greater freedom the mediator had in reacting to the learner' problems in MLE approach in this study brought this approach to DA more than GP in line with the Vygotky's understanding of ZPD as a means of diagnosing development.

\section{References}

Aljaafreh, A., \& Lantolf, J.P. (1994). Negative feedback as regulation and second language learning in the zone of proximal development. The Modern Language Journal, 78 (4), 465-483. doi: 10.1111/j.15404781.1994.tb02064

Berg, B.L. (2001). Qualitative research methods for social sciences. Boston, MA: Allyn \& Bacon.

Birjandi, P., \& Ebadi, S. (2009). Issues in dynamic assessment. English Language Teaching, 2 (4), 188-199.

Brown, A. L., Campione, J. C. (1985). Dynamic assessment: One approach and some initial data (Technical Report No. 361). University of Illinois at Urbana-Champaign.

Brown, A.L., \& French, L.A. (1979). The zone of proximal development: Implication for intelligence testing in the year 2000. Intelligence, 23, 255-273.

Campione, J.C., Brown, A. L., Ferrara, R.A., Bryant, N.R. (1984). The zone of proximal development: Implications for individual differences and learning. New Directions for Child and Adolescent Development, 23, 77-91. doi: 10.1002/cd.23219842308

Cohen, J. (1988). Statistical power analysis for the behavioral sciences. Hillsdale, NJ: Erlbaum

Cioffi, G., \& Carney, J. J. (1983). The dynamic assessment of reading disabilities. Reading Teacher, 36, 764-768.

Duvall, E. (2008). No secrets to conceal: Dynamic assessment and a state mandated, standardized 3rd grade reading test for children with learning disabilities (Unpublished doctoral dissertation). The Pennsylvania State University, Pennsylvania.

Eslami, Z.R. (2010). Teachers' voice vs. students' Voice: A needs analysis approach to English for academic purposes (EAP) in Iran. English Language Teaching, 3 (1), 1-9.

Ferrara, R.A, Brown, A.L., \& Campione, J.C. (1986). Children's learning and transfer of inductive reasoning rules: Studies in proximal development. Child Development, 57 (5), 1087-1099.

Feuerstein, R. Y. (2000). Mediated learning experience, instrumental enrichment, and the learning propensity assessment device. Retrieved on August 2012 from: www.icdl.com/graduate/documents/Chapter22.pdf

Feuerstein R., Feuerstein, R.S. Falik, L., \& Rand, Y. (2006). Mediated learning experience. Retrieved on July 14, 2014 from: http://www.thinkingconnections.org/theory/MLE.shtml.

Hayes, D.J. (2011). Assessing vocabulary in context using Graduated Prompting (Unpublished doctoral dissertation). University of Cincinnati, Ohio.

Jitendra, A. K., \& Kameenui, E.J. (1993). Dynamic assessment as a compensatory assessment approach: A description and analysis. Remedial and Special Education, 14 (5), doi: 10.1177/074193259301400503

Khalifeh, H., \& Weir, C.J. (2009). Examining reading: Research and practice in assessing second language reading. Cambridge: Cambridge University Press.

Lantolf, J. P., \& Poehner, M. E. (2004). Dynamic assessment of L2 development: bringing the past into the future. Journal of Applied Linguistics, 1 (1), 49-72.

Lidz, C. S. (2002). Mediated learning experience (MLE) as a basis for an alternative approach. School Psychology International, 23 (1), 68-84. doi: 10.1177/0143034302023001731

Nassaji, H., \& Cumming, A. (2000). What's in a ZPD: A case study of a young ESL student and teacher interacting through dialogue journals. Language Teaching Research, 4 (2), 95-12. doi: 10.1177/136216880000400202

Phakiti, A. (2003). A closer look at the relationship of cognitive and metacognitive strategy use to EFL reading achievement test performance. Language Testing, 20 (1), 26-56. doi: 10.1191/02655322031t243oa

Poehner, M.E. (2008). Dynamic assessment: A Vygotskian approach to understanding and promoting L2 development. Boston: Springer

Poehner, M.E. (2007). Beyond the Test: L2 dynamic assessment and the transcendence of mediated learning. Modern Language Journal 91 (3), 323-341. doi: 10.1111/j.1540-4781.2007.00583

Poehner, M.E. (2005). Dynamic assessment of oral proficiency among advanced L2 learners of French (Unpublished doctoral dissertation). The Pennsylvania , Pennsylvania State University.

Pourdana, N., Bornaki, F., Moayedi Fard, Z., \& Sarkhosh, S. Z.(2012). Test-taking strategies and performance on reading comprehension tests by Iranian EFL learners. International Journal of Applied Linguistics \& English Literature, 1 (2), 138-153. 


\section{Appendix 1}

Taxonomy of Mediations for MLE Intervention Program (MLET)

\begin{tabular}{|c|c|}
\hline $\begin{array}{c}\text { Reading Comprehension } \\
\text { Domains }\end{array}$ & Mediation Typology \\
\hline MQMs & $\begin{array}{l}\text { Exploring the student's self-strategy } \\
\text { Finding the most frequent word /phrase } \\
\text { Finding the topic } \\
\text { Finding the idea of all the paragraphs } \\
\text { Using the information in the first paragraph } \\
\text { Using the information in the last paragraph } \\
\text { Asking for an explanation }\end{array}$ \\
\hline GQMs & $\begin{array}{l}\text { Exploring the student's self-strategy } \\
\text { Analyzing the word for the suffix or prefix } \\
\text { Checking the meaning of the options } \\
\text { Checking the meaning of the sentence including the option } \\
\text { Asking for an explanation }\end{array}$ \\
\hline IQMs & $\begin{array}{l}\text { Exploring the student's self-strategy } \\
\text { Paraphrasing the question } \\
\text { Considering the prior knowledge } \\
\text { Summarizing } \\
\text { Monitoring discourse structures (comparing, contrasting, describing,..) } \\
\text { Finding the interrelationships using logical connectors } \\
\text { Checking the previous understanding } \\
\text { Asking for an explanation }\end{array}$ \\
\hline
\end{tabular}

*MQMs: Main idea Questions Mediations, GQMs:Guessing Questions Mediations, and IQMs: Inferencing Questions Mediations.

Appendix 2

Mediational Protocol for the GP Intervention Program (the GPMP)

\begin{tabular}{|c|c|}
\hline Prompts typology & Levels of explicitness: Mediation move \\
\hline MQPs & $\begin{array}{l}\text { Prompt 1: Find the topic of the passage (The most frequent word) } \\
\text { Prompt 2: Check whether the idea is supported by the whole paragraph not just one } \\
\text { paragraph } \\
\text { Prompt 3: Find the main idea of the first paragraph } \\
\text { Prompt 4: Provide the correct response and explanation }\end{array}$ \\
\hline GQPs & $\begin{array}{l}\text { Prompt 1: Check the meaning of the options } \\
\text { Prompt 2: Analyze the word for affixes } \\
\text { (This prompt is not used for the word not including affixes) } \\
\text { Prompt 3: Check the meaning of the affix in that word } \\
\text { (This prompt is not used if the word does not include affixes) } \\
\text { Prompt 4: Look for a key word } \\
\text { Prompt 5: Check each option with the passage or the referred paragraph } \\
\text { Prompt 6: Provide the correct response and explanation }\end{array}$ \\
\hline $\begin{array}{l}\text { IQPs } \\
\text { (Without key words in Qs) }\end{array}$ & $\begin{array}{l}\text { Prompt 1: Check the question for your understanding } \\
\text { Prompt 2: Find key words in the question and check them in the passage } \\
\text { Prompt 3: Check your understanding of the sentence in which the key word appears } \\
\text { Prompt 4: Look for the option which is closest in meaning to what you found following } \\
\text { Prompt } 3 \\
\text { (This prompt is not used for the negative questions) } \\
\text { Prompt 5: Check the idea of each option (looking for the key words' synonyms or } \\
\text { antonyms in order to delete the irrelevant or incorrect options) } \\
\text { Prompt 6: Provide the correct response and explanation } \\
\text { Prompt 1: Get the main idea of the referred paragraph } \\
\text { Prompt 2: Find the option in which this main idea is expressed } \\
\text { (This prompt is not used for the negative questions) } \\
\text { rompt 3: Check the idea of each option (looking for the key words' synonyms or antonyms } \\
\text { in order to delete the irrelevant or incorrect options) } \\
\text { Prompt 4: Provide the correct response and explanation }\end{array}$ \\
\hline
\end{tabular}

*MQPs: The prompts for Main idea Questions, GQP: Prompts for Guessing the meaning of the new words Questions, IQPs (With key words in Question items): Prompts for Inferencing Questions in which there is a key word to be followed in the passage, IQPs (without key words): Prompts for Inferencing Question items in which no key word is given. 


\section{Appendix 3}

Cognitive and Metacognitive Strategy Awareness Questionnaire (CMSQ)English Version

$\mathrm{N}$ Item 1 \begin{tabular}{ccccc}
\hline & 2 & 3 & 4 & 5
\end{tabular}

1 I made short notes or underlined main ideas during the test.

2 I translated the reading texts and tasks into Persian.

3 I used pictures or titles of the texts to help comprehend reading text.

4 I used my own English structure knowledge to comprehend the text

5 I spent more time on difficult questions.

6 I tried to understand the texts and questions regardless of my vocabulary knowledge

$7 \quad$ I tried to find topics and main ideas by scanning and skimming.

8 I read the texts and questions several times to better understand them.

9 I used my prior knowledge to help understand the reading text.

10 I tried to identify easy and difficult test components.

11 I looked at the scores of each part to determine the weight of scores before starting to complete the test.

12 I determined which parts were more important than others before starting the test.

13 When I started to complete the test, I planned how to complete the test and followed the plan

14 I was aware of what and how I was doing in the test.

15 I checked my own performance and progress while completing the test

16 I attempted to identify main points of the given reading the tests

17 I thought through the meaning of the test tasks/ questions before answering them

18 I was aware of which strategy to use and how and when to use it.

19 I would correct mistakes immediately when found

20 I asked myself how the test questions and the given texts related to what I already knew

21 I determined what the test tasks/questions required me to do

22 I was aware of the need to plan a course of action

23 I was aware of how much the test remained to be completed

24 I tried to understand the questions adequately before attempting to find the answers

25 I made sure I understood what had to be done and how to do it.

26 I was aware of my ongoing thinking process

27 I kept track of my own progress to complete the questions on time

28 I used multiple thinking strategies to help answer the test questions

29 I made sure to clarify the goal and know how to complete it.

30 I was aware of the selected strategies to help me complete the test questions before solving them.

31 I checked my accuracy as I progressed through the test

32 I selected relevant information to help me understand the reading texts

33 I determined how to solve the test.

34 I carefully checked the answers before submitting the test.

35 ed relevant information to help me understand the reading texts and answer the test questions 